DOI: $\underline{\text { https://doi.org/10.24867/12GI05Simeunovic }}$

\title{
UNAPREĐENJE SISTEMA UPRAVLJANJA FARMACEUTSKIM OTPADOM NA PODRUČJU BRČKO DISTRIKTA
}

\section{IMPROVEMENT OF THE PHARMACEUTICAL WASTE MANAGEMENT SYSTEM IN THE BRCKO DISTRICT}

\author{
Jovana Simeunović, Fakultet tehničkih nauka, Novi Sad
}

\begin{abstract}
Oblast - INŽENJERSKI MENADŽMENT
Kratak sadržaj - U radu je prikazan problem upravljanja farmaceutskim otpadom na području Brčko distrikta. Korišćenjem određene metodologije (ISHIKAWA $i$ FMEA metoda) identifikovani su osnovni uzroci problema, a primenjivanjem principa povratne $i$ zelene logistike predložene su određene mere unapređenja.
\end{abstract}

Ključne reči: Upravljanje otpadom, ISHIKAWA, FMEA, povratna i zelena logistika

Abstract - This work presents the problem of pharmaceutical waste management in the Brcko District. Using a certain methodology (ISHIKAWA and FMEA method), the basic causes of the problem were identified, and by applying the principles of return and green logistics, certain improvement measures were proposed.

Keywords: Waste Management, ISHIKAWA, FMEA, Reverse and Green Logistics

\section{UVOD}

Nastanak otpada posljedica je svake ljudske aktivnosti. Razvojem nauke i tehnologije čovjek je prestao biti potrošač prirodnih proizvoda, nego je prešao u kreatora prirodnih procesa, što neizbežno dovodi do poremećaja prirodne ravnoteže. Ova činjenica dovela je do nekontrolisane potrošnje prirodnih resursa, što rezultira sve manje resursa na planeti Zemlji uz stvaranje velike količine otpada.

Veliku pažnju treba usmeriti na otpad koji nastaje u zdravstvenim ustanovama. Otpad nastao pružanjem zdravstvenih usluga mešavina je komunalnog i medicinskog otpada. Zagađenje uzrokovano opasnim medicinskim otpadom ne samo da ima velik uticaj na ljudsko zdravlje, već i na ekosistem u koji se odlaže. Da bi se održala zdrava okolina, problem zbrinjavanja medicinskog otpada mora se prepoznati kao važan zadatak svih struktura društva koje učestvuju u njegovom stvaranju.

Zbog toga je izuzetno važno uspostaviti adekvatan sistem prikupljanja i upravljanja otpadom, vodeći računa od samog početka, tj. od mesta nastanka otpada preko sakupljanja te konačne neutralizacije štetnog uticaja zbog budućih generacija.

\footnotetext{
NAPOMENA:

Ovaj rad proistekao je iz master rada čiji mentor je bio dr Nebojša Brkljač, docent.
}

\section{POVRATNA I ZELENA LOGISTIKA}

Logistika je veoma stara oblast koja se vremenom usavršavala. U literaturi postoje razne definicije koje je objašnjavaju, a jednu od njih dala je i američka organizacija, odnosno udruženje stručnjaka za upravljanje lancima snabdevanja i ona glasi: „Logistika je proces planiranja, implementacije i upravljačkih procedura za efikasno i efektivno transportovanje i skladištenje robe, uključujući i usluge i sa njima povezane informacije od mjesta nastanka do mjesta potrošnje." Jedna od definicija povratne logistike jeste: „Povratna logistika je proces planiranja, implementacije i upravljanja efektivnim i efikasnim tokom sirovina, poluproizvoda, gotovih proizvoda i pripadajućih infomacija, od tačke potrošnje do tačke porijeka s ciljem obnavljanja vrednosti ili adekvatnog odlaganja.“

Predmet povratne logistike je [1]:

- materijal koji nastaje tokom procesa proizvodnje

- neispravan proizvod koji je greškom dostavljen kupcu, koji je otkazao kod korisnika tokom garantnog roka ili koji je poslat na popravku

- ispravan proizvod koji je zastareo

- proizvod kojem je istekao rok trajanja ili čiji je radni vek istekao

- ambalaža korišćena kao zaštita tokom transporta.

Povratna logistika se odvija kroz procese koji obuhvataju tok proizvoda od tačke upotrebe odnosno potrošača do tačke nastanka odnosno proizvođača. Aktivnosti povratne logistike mogu se podeliti u sledeće grupe [1]:

- Sakupljanje

- Pregled i sortiranje

- Obnavljanje vrijednosti proizvoda (popravka, renovacija, kanibalizacije, reciklaža, itd.)

- Konačno odlaganje (usled neisplativosti tretiranja)

- Vraćanje na tržište.

Zelena logistika insistira na smanjenju potrošnje energije naročito iz neobnovljivih izvora, smanjenju upotrebe neženjenih materijala i smanjenju troškova transporta. Osnovni cilj zelene logistike je da smanji negativan uticaj logističkih aktivnosti na okolinu [2]. Koncept zelene logistike sadrži nekoliko kontradiktornosti. Paradoksi primene zelene logistike su [1]:

$$
\begin{aligned}
& \text { - Vreme, fleksibilnost i pouzdanost } \\
& \text { - Prostorni raspored (mreža) } \\
& \text { - Skladištenje. }
\end{aligned}
$$

\section{UPRAVLJANJE OTPADOM}

$\mathrm{S}$ obzirom da će u radu glavni naglasak biti na farmaceutskom otpadu u nastavku će se definisati osnovni poj- 
movi vezani za otpad uopšteno pa do krajnjeg objašnjenja pojma farmaceutskog otpada.

\subsection{Opasan otpad}

Otpad kao osnovni zagađivač životne sredine, predstavlja sav materijal ili predmeti koji nastaju u toku obavljanja delatnosti, a koji više nisu pogodni za dalju upotrebu i moraju se adekvatno odbaciti [3]. Prema Zakonu o upravljanju otpadom definicija otpada je sledeća:

„Otpad predstavlja sve materije ili predmete koje vlasnik odlaže, namerava odložiti ili mora odložiti saglasno jednoj od kategorija otpada navedenoj u listi otpada osvojenoj posebnim zakonskim propisom“"

Opasan otpad je svaki otpad koji ima jedno od svojstava: eksplozivnost, zapaljivost, reaktivnost, toksičnost, nagrizanje, nadražljivost, infektivnost, kancerogenost, mutagenost, svojstvo ispuštanja otrovnih gasova hemijskom reakcijom ili biološkom razgradnjom, kao i amabalaža u kojoj se otpad nalazi [4]. Prema definiciji Zakona o upravljanju otpadom definicija opasnog otpada glasi:

„Opasan otpad znači svaki otpad koji je utvrđen posebnim propisima i koji ima jednu ili više karakteristika datih $u$ podzakonskom aktu koji donosi gradonačelnik na prijedlog ovlaštenog odeljenja, koji prouzrokuje opasnost po zdravlje ljudi i životnu okolinu, po svom poreklu, sastavu ili koncentraciji, kao i onaj otpad koji je naveden $\mathrm{u}$ katalogu otpada kao opasni $\mathrm{i}$ regulisan posebnim propisom."

\subsection{Medicinski otpad}

Postoje razne definicije medicinskog otpada, ali suštinu svake definicije čini činjenica da on nastaje u zdravstvenim ustanovama, a vezan je za obavljanje medicinskih procedura: dijagnostike, lečenja ili istraživačkog rada. U zdravstvenim ustanovama sav medicinski otpad koji nastaje je heterogenog karaktera:

- opasan medicinski otpad i

- inertni-komunalni otpad.

\subsection{Farmaceutski otpad}

Farmaceutski otpad se može najlakše definisati kao lekovi kojima je istekao rok upotrebe, ali je ovo ipak samo usko značenje. Prava definicija farmaceutskog otpada glasi:

„Farmaceutski otpad je medicinski otpad koji obuhvata lekove, medicinska sredstva uključujući i njihovu primarnu ambalažu koji su postali neupotrebljivi zbog isteka roka trajanja, prolivanja, rasipanja, pripremljeni, a neupotre-bljeni ili se ne mogu više koristiti iz nekih drugih razloga."

\subsection{Rizik od farmaceutskog otpada}

Mnogi od hemijskih preparata koji se upotrebljavaju u zdravstvenoj zaštiti su rizični po zdravlje. Ukoliko se otpadom neadekvatno rukuje on može biti izvor svih vrsta infekcija: respiratornih, gastrointestinalnih, kožnih, urinarnih, infekcija koje se prenose putem krvi ili drugih telesnih tečnosti.

Kada se lekovi odlože u otpad ili u kanalizaciju farmaceutski spojevi dospevaju u okolinu i u reke i jezera odakle ih apsorbuju biljke, životinje i ljudi. Ovo pred- stavlja veliku opasnost koja ne samo da urožava životinjski svet i ljudsko zdravlje, nego i moderni pogoni nisu u mogućnosti da prečiste vodu od farmaceutskih supstanci.

\subsection{Katalog otpada}

Prateći evropske trendove i $\mathrm{BiH}$ je izdala Pravilnik o kategorijama otpada sa listama koji je usklađen sa Evropskim katalogom otpada. Ovaj dokument predstavlja spisak otpada prema osobinama i delatnostima iz kojih potiče i svrstava se $u$ dvadeset grupa. Opasan otpad $u$ katalogu otpad ima oznaku zvezdice (*). Prema Evropskom katalogu otpada medicinski otpad je definisan kao otpad koji nastaje pri pružanju zdravstvene zaštite $u$ medicini i veterini i srodnim istraživanjima i zaveden je pod brojem 180000 sa podskupovima.

\subsection{Zakonodavni okvir}

Upravljanje medicinskim otpadom u $\mathrm{BiH}$ regulisanom je entitetskim i kantonalnim zakonima i podzakonskim aktima. Na nivou Federacije BiH, Republike Srpske i Brčko distrikta definisani su zakoni i propisi kojima se oblast otpada uređuje. Pored njih postoje i strateški dokumenti koji se tiču ove oblasti. Pridruživanje Evropskoj Uniji je cilj kome se Bosna i Hercegovina posvetila potpisivanjem Sporazuma o stabilizaciji i pridruživanju 2008. godine. Zemlje koje žele da se pridruže EU imaju obavezu da svoje zakone prilagode zakonima $\mathrm{EU}$, pa tako i $\mathrm{BiH}$ bi trebalo da postepeno usklađuje svoje zakonodavstvo.

\section{TRETMAN FARMACEUTSKOG OTPADA NA PODRUČJU BRČKO DISTRIKTA}

Farmaceutski otpad, tj. neiskorišćeni lekovi stanovnici Brčko distrikta najčešće odlažu zajedno sa komunalnim otpadom što za posledicu ima da on završava na gradskoj deponiji. Grad takođe nema razvijenu infrastrukturu za organizovano odvajanje opasnog otpada što je najveći nedostatak kada je reč o upravljanju otpadom. Bolnica $u$ Brčkom poseduje spalionicu organskog otpada, ali isključivo za svoje potrebe. Za zbrinjavanje infektivnog otpada poseduje sterilizator - autoklav. Farmaceutski otpad se najviše izvozio, ali konkretni podaci o mjestu gde se izvozio i kako se sakupljao ne postoje. Samo određene firme imaju sklopljene ugovore sa ustanovama koje preuzimaju opasan otpad i zbrinjavaju ga na ekološki prihvatljiv način. Zakonodavstvo i pravilnici u kojima je tematika medicinskog otpada tretirana definisano je kako se medicinski otpada tretira, ali glavni nedostatak je što se na nivou države ti propisi sporo ili uopšte ne sporovode. Države u kojima se izvozi opasan otpad su prema podaku iz 2009. godine su Austrija, Slovenija i Francuska. Na nivou Brčko distrikta se ne vodi evidencija ni o količinama farmaceutskog otpada, što znači da ne postoje statistički podaci o proizvodnji ovog otpada. Ista situacija je i na nivou države. Ni entiteti nemaju sistem za registrovanje količine proizvedenog otpada. U strateškim i planskim dokumentima entiteta postoje određene informacije o količinama otpada, ali su one najčešće oprečne i pokazuju veliku kontradiktornost. Ipak, ti podaci će poslužiti kako bi se mogla utvrditi procenjena količina otpada na području Brčko distrikta. Struktura medicinskog otpada koja se može uzeti kao mjerodavna, je sledeća: 
- komunalni otpad $85,53 \%$

- patološki i infektivni otpad 13,50\%

- hemijski i farmaceutski otpad 0,15\%,

- oštri predmeti i lancete $0,58 \%$ i

- specijalni opasni otpad (citostatici) 0,23\%.

Ova raspodela će biti osnova za procenjivanje količina farmaceutskog otpada na području Brčko distrikta zajedno sa prethodno navedenim podacima izvučenih na nivou entiteta.

\subsection{Procena količina farmaceutskog otpada na području Brčko distrikta}

S obzirom da na prostru Brčkog uopšte ne postoje podaci o količinama bilo koje vrste otpada, u ovom poglavlju biće procenjena količina farmaceutskog otpada. Procena će se vršiti na osnovu uporednih podataka iz susednih regija Bijeljina i Doboj budući da su podaci iz istih dostupni u strateškim dokumentima Republike Srpske.

Tabela 1. Količine medicinskog otpada

\begin{tabular}{llcc}
\hline \multirow{2}{*}{ Regija } & $\begin{array}{l}\text { Broj } \\
\text { stanovnika }\end{array}$ & \multicolumn{2}{c}{$\begin{array}{c}\text { Količina medicinskog } \\
\text { otpada (tone) }\end{array}$} \\
\cline { 3 - 4 } & 133.681 & $\mathbf{2 0 1 3 .}$ & $\mathbf{2 0 1 6 .}$ \\
\hline Bijeljina & 206.897 & 145 & 21 \\
\hline Doboj & 83.516 & 441 & 17 \\
\hline Brčko & & - & - \\
\hline
\end{tabular}

Ukupna količina farmaceutskog otpada na području Brčko distrikta:

2013:

$$
N_{f}=N_{m} * k_{f}=144 t * 0,0015=0,216 t=216 k g
$$

2016:

$$
N_{f}=N_{m} * k_{f}=9,5 t * 0,0015=0,01397 t=14 k g
$$

Pored ove metodologije, procena se može izvršiti i na osnovu prosečne količine medicinskog otpada po osobi. U FBiH ukupna proizvodnja medicinskog otpada je 2,2 $\mathrm{kg} /$ osobi/god, dok je u RS taj broj nešto veći 2,45 $\mathrm{kg} /$ osobi/god.

$$
\begin{gathered}
N_{f}=N_{m} * k_{f}=194 t * 0,0015=0,2913 t \\
=291 \mathrm{~kg} / \mathrm{god}
\end{gathered}
$$

$\mathrm{Na}$ osnovu date procene može se zaključiti da se količine farmaceutskog otpada kreću okvirno između 200 kilograma do 300 kilograma na godišnjem nivou. Može se reći da su ovo male količine kada se uporedi sa prosečnom količinom prodatih lijekova u toku godine.

U proseku dnevna količina prodatih lijekova iznosi $8 \mathrm{~kg}$. [5] Na teritoriji Brčkog postoje 67 registrovanih apoteka. [6] Ovo znači da se na teritoriji Brčko distrikta na godišnjem nivou proda približno 200 tona farmaceutskih proizvoda.

\section{ANALIZA PROBLEMA I PREDLOG MERA UNAPREĐENJA}

$\mathrm{Na}$ osnovu snimka stanja utvrđeni su osnovni uzroci problema koji će biti osnov za rešavanje problema.

\subsection{Identifikacija potencijalnih uzroka}

Identifikovani uzroci problema su raspoređeni po grupama i prikazani na sledećoj slici Ishikawa dijagrama.

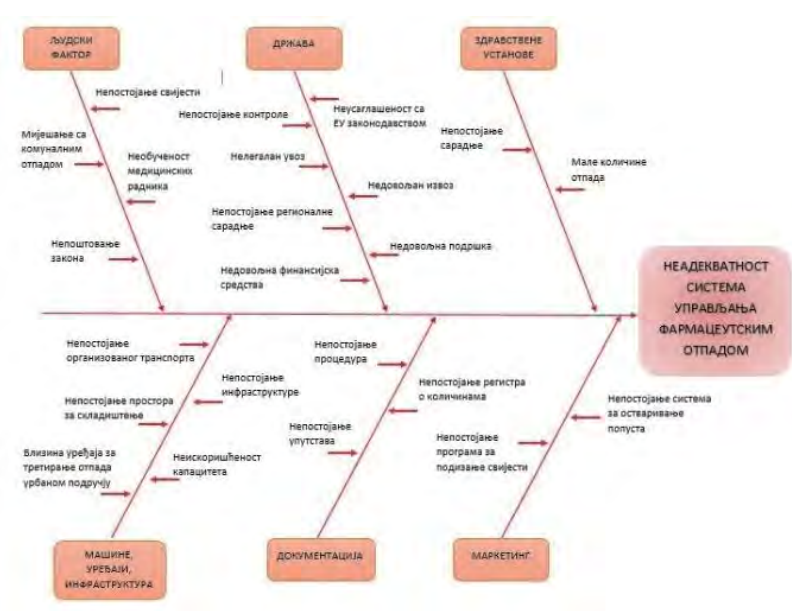

Slika 1. Ishikawa dijagram

\subsection{Ocenjivanje potencijalnih uzroka}

Posle utvrđivanja potencijalnih uzroka i njihove klasifikacije u odgovarajuće grupe izvršiće se njihovo ocenjivanje prema kriterijumima: težina, verovatnoća i detekcija, na osnovu FMEA metode. U neprihvatljivim rizicima, na osnovu RPN, našli su se sledeći rizici:

- Mešanje sa komunalnim otpadom

- Nepostojanje svesti građana o značaju adekvatnog odlaganja otpada

- Male količine otpada

- Nelegalan uvoz

- Neobučenost medicinskih radnika za rad sa opasnim otpadom

- Nedovoljan izvoz

- Nedovoljna podrška države

\subsection{Predlog mera unapređenja}

Unapređenje sistema prikupljanja farmaceutskog otpada na teritoriji Brčko distrikta daće doprinos u mnogim sferama i to:

- Bezbednost u radu zdravstvenih radnika

- Bezbednost korisnika zdravstvene zaštite

- Smanjenje količine farmaceutskog otpada

- Smanjenje rizika od širenja zaraznih bolesti

- Očuvanje životne sredine.

$\mathrm{Da}$ bi se postiglo unapređenje sistema potrebno je osmisliliti rešenje kojim će se uticaj identifikovanih rizika smanjiti ili u najboljem slučaju eliminisati. Samim tim rešenje će se ogledati kroz četiri faze u okviru kojih će biti tretirani već identifikovani neprihvatljivi rizici:

\section{- Obezbeđenje podrške države}

Veoma je bitno uticati da vlast prepozna ozbiljnost ovog problema. U okviru ove faze predlaže se da se u okviru budžeta Brčko distrikta obezbede određena finansijska sredstva radi uspostavljanja efikasnog sistema upravljanja farmaceutskim otpadom.

- Sprovođenje programa podizanja svesti građana Predlaganje programa kojim će se podići svest građana o opasnostima farmaceutskog otpada imaće i za cilj da se spreči mešanje sa komunalnim otpadom. U okviru programa se predlaže da se građanima uz redovne račune uručuju leci na kojima će biti detaljno objašnjenje kako se pravilno rukuje farmaceutskim otpadom. Takođe bi trebalo koristiti i postere za izloge i obaveštenja koja će apoteke, a i druge zdravstvene ustanove postaviti kako bi obavestile javnost da je moguće besplatno predati 
neupotrebljive lekove. Organizovanje akcija prikupljanja starih lekova je isto tako dio programa za podizanje svesti građana, a sve u cilju da se negativan uticaj ovog otpada umanji, a građanima će biti i dostupna internet stranica na kojima će se moći dodatno informisati o otpadu i njegovom štetnom dejstvu.

- Sprovođenje obuke medicinskih/zdravstvenih radnika Direktori i rukovodioci zdravstvenih ustanova treba da obezbede sprovođenje obuke za upravljanje medicinskim otpadom od strane zvaničnih institucija. Obuka treba da obuhvati upoznavanje sa osnovnim zakonskim propisima koji se tiču medicinskog otpada, sa zdravstvenim rizicima, zatim sa kategorijama medicinskog otpada i najznačajnije kako se pravilno rukuje medicinskim otpadom kako bi se očuvala sopstvena bezbednost, bezbednost pacijenata i okoline.
- Unapređenje sistema upravljanja farmaceutskim otpadom

Upravljanje farmaceutskim otpadom odvijaće se dvojako: $\mathrm{u}$ zdravstvenim ustanovama i putem prikupljanja od građana.

\subsection{Akcioni plan}

Kroz akcioni plan su detaljno predstavljene aktivnosti koje je neophodno sprovesti kako bi se dovelo do unapređenja sistema upravljanja farmaceutskim otpadom. Takođe, dati su i podaci o dinamici realizacije istih kao i finansijska sredstva koja su potrebna za sprovođenje. Finansiranje bi isključivo bilo iz budžeta Brčko distrikta i kroz međunarodnu pomoć.

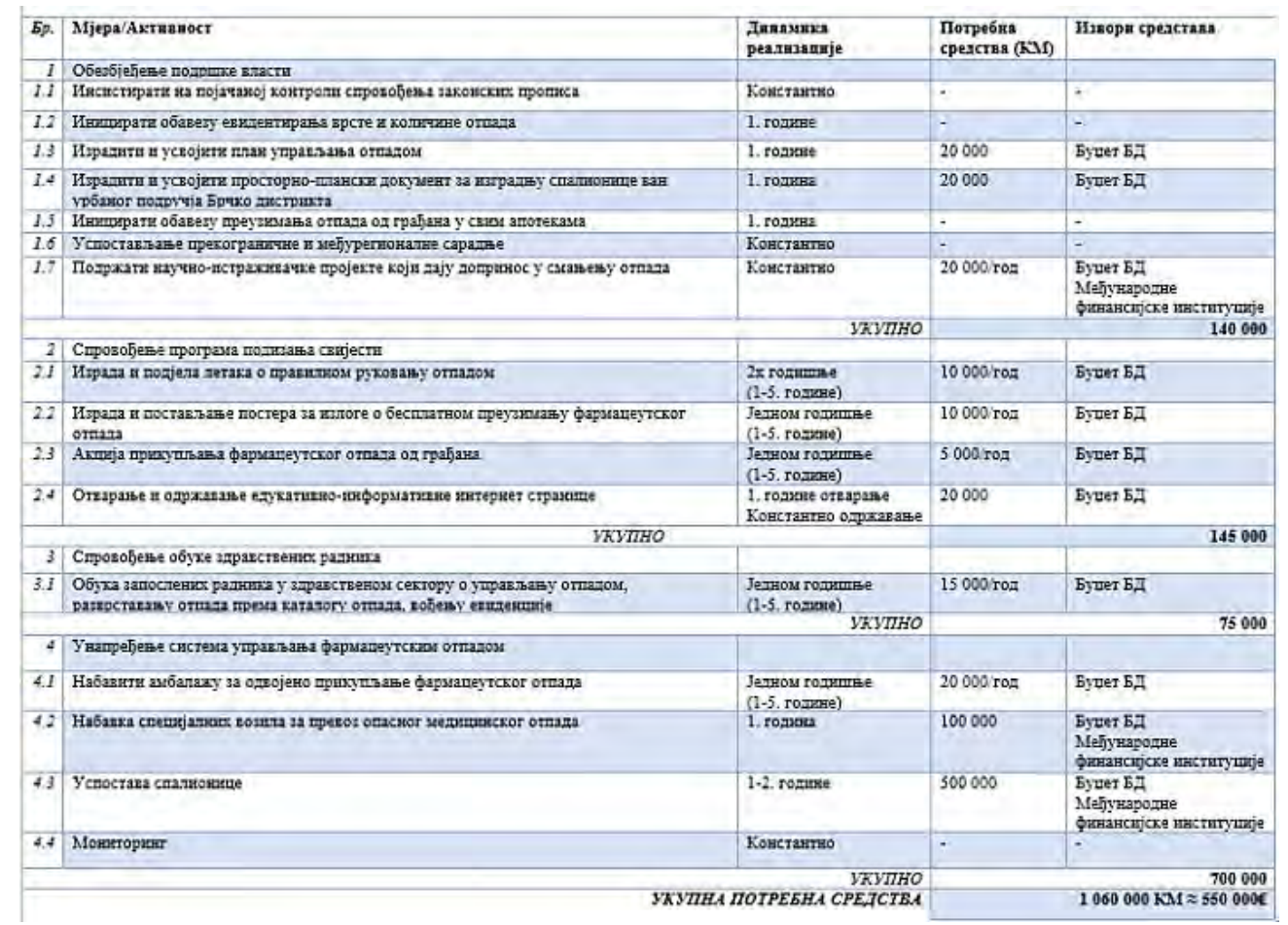

\section{ZAKLJUČAK}

Sprovođenjem rešenja značajno bi se smanjili, a neki rizici čak i eliminisali. Predloženom organizacijom prikupljanja lekova, uz podršku države, količine farmaceutskog otpada bi se svele na minimum što bi dalo doprinos životnoj sredini i javnom zdravlju. Finansijskom podrškom vlasti, kao i međunarodnom finansijskom pomoći bi se omogućile da se definisane aktivnosti u akcionom planu sprovode bez ometanja, a sve u cilju obezbeđenja zdrave okoline.

Unapređenje sistema upravljanja farmaceutskim otpadom treba posmatrati kao sastavni dio brige o zdravlju. Ugrožavanje zdravlja zbog neadekvatnog odlaganja otpada, ne samo da ruši ugled celokupnom zdravstvenom sistemu nego i budućim generacijama ostavlja ekološko narušenu sredinu.

\section{LITERATURA}

[1] Šević, D., Brkljač, N. (2018). Povratna i zelena logistika. Novi Sad. cioni plan

[2] Nikoličić, S., Lazić, D. (2006). Zelena logistika. Festival kvaliteta. Kragujevac.

[3] Otpad i upravljanje otpadom. Preuzeto sa sajta Agencije za zaštitu životne sredine; Ministarstvo zaštite životne sredine republike Srbije.

[4] Šević , D. Materijal sa predavanja. Sistem upravljanja zaštitom životne sredine. Novi Sad.

[5] Upravljanje medicinskim otpadom u sjeveroistočnoj Bosni i Hercegovini. Tuzla: Centar za ekologiju. (2011)

[6] Registar poslovnih subjekata Brčko distrikta.

\section{Kratka biografija:}

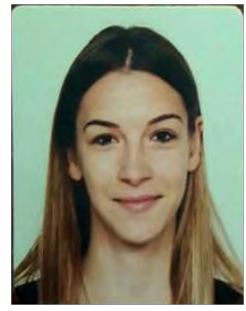

Jovana Simeunović rođena je u Novom Sadu 1995. god. Diplomski rad na Fakultetu tehničkih nauka odbranila je 2018. god.

kontakt: jovanas95@hotmail.com 